(c) American Dairy Science Association, 2006.

\title{
Technical Note: A Rapid Pulsed-Field Gel Electrophoresis Method for Analysis of Bifidobacteria
}

\author{
E. P. Briczinski and R. F. Roberts ${ }^{1}$ \\ Department of Food Science, The Pennsylvania State University, University Park 16802
}

\begin{abstract}
Pulsed-field gel electrophoresis (PFGE) is a widely used and highly discriminatory molecular typing method that has been applied to bifidobacteria. However, published PFGE protocols used with bifidobacteria require between 5 and $7 \mathrm{~d}$ to complete. A rapid PFGE method was developed that can be completed within $24 \mathrm{~h}$.
\end{abstract}

Key words: pulsed-field gel electrophoresis, Bifidobacterium

As the amount of scientific evidence supporting the reported health benefits of probiotics has risen, interest has grown in adding probiotic organisms to dairy products and to pharmaceutical preparations. A number of selection criteria have been proposed for probiotic microorganisms and, in addition to the various functional, technological, and safety criteria, appropriate methods must exist to differentiate one strain from another (Mattila-Sandholm et al., 2002; Champagne et al., 2005). Nucleic acid-based techniques have become increasingly important in differentiating and typing bacteria and in providing a means for evaluating interand intraspecies relatedness (Busch and Nitschko, 1999). Pulsed-field gel electrophoresis (PFGE) is a widely used and highly discriminatory molecular typing method based on comparison of fragment patterns of restriction-digested chromosomal DNA (Basim and Basim, 2001). Various researchers have applied PFGE to Bifidobacterium strains to estimate chromosome size (Bourget et al., 1993), to assess differences within and between human fecal samples (McCartney et al., 1996; Kimura et al., 1997; Rosberg-Cody et al., 2004), and to differentiate strains (Roy et al., 1996; Simpson et al., 2003; Yeung et al., 2004). However, reported PFGE protocols used with bifidobacteria are not conducive to routine analysis, requiring between 5 and $7 \mathrm{~d}$ to complete the assay. The objective of this research was to

Received October 4, 2005.

Accepted February 23, 2006.

${ }^{1}$ Corresponding author: rfr3@psu.edu develop a PFGE protocol that could be applied to bifidobacteria and that could be completed within $24 \mathrm{~h}$.

Twelve strains of Bifidobacterium were obtained from the ATCC (American Type Culture Collection, Manassas, VA) and the DSMZ (Deutsche Sammlung von Mikroorganismen und Zellkulturen $\mathrm{GmbH}$, the German Collection of Microorganisms and Cell Cultures, Braunschweig, Germany), and 22 samples of Bifidobacterium were obtained from 6 commercial starter culture companies (Table 1). All strains were identified as Bifidobacterium by PCR amplification of a region of $16 \mathrm{~S}$ rDNA based on the method of Kaufmann et al. (1997). Commercial strains were identified at the species level using PCR primers under the conditions described by Matsuki et al. (1999), Ventura et al. (2001), and Ventura and Zink (2002). Suspensions of strains from ATCC, DSMZ, and from commercial starter culture companies (4 strains: 2 Bifidobacterium animalis ssp. lactis, 1 Bifidobacterium infantis, and 1 Bifidobacterium longum) were prepared and separated into duplicate aliquots to compare the typical and modified protocols. All strains were then evaluated using the modified protocol. Comparisons of the typical and modified methods were replicated twice. The modified protocol was replicated with all strains at least in triplicate.

For PFGE, strains were streaked onto liver lactose agar (35 g/L liver infusion broth, $10 \mathrm{~g} / \mathrm{L}$ lactose, $10 \mathrm{~g} /$ L trypticase peptone, $2 \mathrm{~g} / \mathrm{L}$ sodium chloride, $15 \mathrm{~g} / \mathrm{L}$ agar; Enumeration Procedures for Probiotics, Lyoferm, Inc., Indianapolis, IN) and incubated anaerobically for $3 \mathrm{~d}$ at $37^{\circ} \mathrm{C}$ in an anaerobic incubator $(5 \mathrm{mmHg}$ vacuum pressure; anaerobic mixed gas: $10 \%$ carbon dioxide, $5 \%$ hydrogen, 85\% nitrogen; VWR, West Chester, PA). A single colony was transferred to $10 \mathrm{~mL}$ of liver lactose broth and incubated anaerobically overnight until turbid. A 2.0-mL aliquot was centrifuged for $10 \mathrm{~min}$ at $14,000 \times g$ to pellet the cells, which were then washed once with $2.0 \mathrm{~mL}$ of $100 \mathrm{~m} M$ Tris, $100 \mathrm{~m} M$ EDTA buffer (pH 7.6) and resuspended in $600 \mu \mathrm{L}$ of this buffer. This suspension was separated into duplicate $160-\mu \mathrm{L}$ aliquots to compare the typical and modified PFGE protocols. To the $160 \mu \mathrm{L}$ of cell suspension used with the typical protocol was added an additional $50 \mu \mathrm{L}$ of the resuspension buffer to account for the dilution effect of 
Table 1. Strains of Bifidobacterium spp. evaluated in this study

\begin{tabular}{ll}
\hline Strain name $^{1}$ & Strain identity \\
\hline ATCC 15696 & Bifidobacterium bifidum \\
ATCC 15697 & Bifidobacterium infantis \\
ATCC 15698 & Bifidobacterium breve \\
ATCC 15700 & B. breve \\
ATCC 15707 & Bifidobacterium longum \\
ATCC 15708 & B. longum \\
ATCC 25527 & Bifidobacterium animalis ssp. animalis \\
ATCC 27536 & B. animalis ssp. lactis \\
ATCC 27672 & B. animalis ssp. animalis \\
ATCC 27686 & Bifidobacterium choerinum \\
ATCC 29521 & B. bifidum \\
DSMZ 10140 & B. animalis ssp. lactis \\
& B. animalis ssp. lactis (20 commercial strains) \\
& B. infantis (1 commercial strain) \\
& B. longum (1 commercial strain) \\
\hline
\end{tabular}

${ }^{1}$ ATCC $=$ American Type Culture Collection (Manassas, VA); DSMZ = Deutsche Sammlung von Mikroorganismen und Zellkulturen $\mathrm{GmbH}$ (German Collection of Microorganisms and Cell Cultures, Braunschweig, Germany).

adding lysis reagents during plug preparation with the modified PFGE protocol.

The "typical" protocol selected was based on that described by Simpson et al. (2002, 2003), which is representative of the PFGE methods found in the bifidobacteria literature. Briefly, the cell suspension was mixed with an equal volume of $2 \%$ InCert agarose (Cambrex, Rockland, ME) prepared in 0.125 $M$ EDTA ( $\mathrm{pH} 7.6$ ) and dispensed into disposable plug molds $(10 \times 5 \times 1.5 \mathrm{~mm}$; Bio-Rad, Hercules, CA). The plugs were incubated in 1 $\mathrm{mL}$ of $1 M \mathrm{NaCl}, 6 \mathrm{~m} M$ Tris-HCl, $100 \mathrm{~m} M$ EDTA, $1 \%$ Sarkosyl buffer (pH 7.6; Sigma, St. Louis, MO) with 10 $\mathrm{mg} / \mathrm{mL}$ lysozyme (Sigma) and 500 units $/ \mathrm{mL}$ mutanolysin (Promega Corp., Madison, WI) at $37^{\circ} \mathrm{C}$ for $18 \mathrm{~h}$. The plugs were then incubated in fresh Sarkosyl buffer with $0.8 \mathrm{mg} / \mathrm{mL}$ proteinase $\mathrm{K}$ (Sigma) at $37^{\circ} \mathrm{C}$ for $18 \mathrm{~h}$. The proteinase $\mathrm{K}$ buffer was refreshed and the plugs were then incubated for an additional $18 \mathrm{~h}$. The plugs were washed twice with $1 \mathrm{~m} M$ phenylmethylsulfonyl fluoride (PMSF; Sigma) in $10 \mathrm{~m} M$ Tris-HCl, $1 \mathrm{~m} M$ EDTA ( $\mathrm{pH} 8.0)$ at $37^{\circ} \mathrm{C}$ for $60 \mathrm{~min}$ in a shaking water bath (New Brunswick Scientific, Edison, NJ). Two slices (1-mm wide) were prepared from the plugs and washed 3 times in $1 \mathrm{~mL}$ of $10 \mathrm{~m} M$ Tris-HCl, $0.1 \mathrm{~m} M$ EDTA (pH 8.0) for $15 \mathrm{~min}$ at room temperature. The slices were preincubated at $4^{\circ} \mathrm{C}$ for $30 \mathrm{~min}$ in $100 \mu \mathrm{L}$ of the appropriate restriction endonuclease buffer. They were then transferred to $100 \mu \mathrm{L}$ of a fresh restriction digest mix-

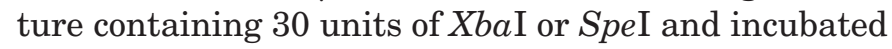
at $37^{\circ} \mathrm{C}$ for $18 \mathrm{~h}$.

To the cell suspension were added $40 \mu \mathrm{L}$ of lysozyme solution $(100 \mathrm{mg} / \mathrm{mL})$ and $10 \mu \mathrm{L}$ of proteinase K solution $(20 \mathrm{mg} / \mathrm{mL})$. This mixture was immediately combined with an equal volume of $1.6 \%$ InCert agarose prepared in $0.1 \%$ SDS (International Biotechnologies, Inc., New Haven, CT) and dispensed into disposable plug molds. Lysis was performed by incubating the plugs in $1.5 \mathrm{~mL}$ of $0.5 M$ EDTA, 1\% Sarkosyl buffer (pH 9.0) with $4 \mathrm{mg} /$ $\mathrm{mL}$ lysozyme and 200 units $/ \mathrm{mL}$ mutanolysin at $55^{\circ} \mathrm{C}$ for $90 \mathrm{~min}$; the plugs were then incubated in fresh Sarkosyl buffer with $0.5 \mathrm{mg} / \mathrm{mL}$ proteinase $\mathrm{K}$ at $55^{\circ} \mathrm{C}$ for $60 \mathrm{~min}$. The plugs were washed in preheated sterile distilled water at $50^{\circ} \mathrm{C}$ for $15 \mathrm{~min}$, then in 3 changes of preheated $10 \mathrm{~m} M$ Tris, $1 \mathrm{~m} M$ EDTA buffer $(\mathrm{pH} 7.6)$ at $50^{\circ} \mathrm{C}$ for $15 \mathrm{~min}$ in a shaking water bath at $75 \mathrm{rpm}$. Two slices were prepared from the plugs and incubated in $100 \mu \mathrm{L}$ of a restriction digest mixture with 30 units of $X b a \mathrm{I}$ or SpeI for $2 \mathrm{~h}$ at $37^{\circ} \mathrm{C}$.

Electrophoresis was performed on $1.0 \%$ SeaKem Gold agarose gel (Cambrex; Michaud et al., 2001) using 0.5× TBE buffer ( $45 \mathrm{~m} M$ Tris, $45 \mathrm{~m} M$ boric acid, $1 \mathrm{~m} M$ EDTA, $\mathrm{pH}$ 8.0). Slices from the traditional and modified methods, from the same initial cell preparation, were loaded in adjacent lanes for comparison. A lambda ladder (BioRad) was included as a molecular weight marker. Electrophoresis was performed using a CHEF Mapper System (Bio-Rad). Switch times were increased linearly from 0.19 to $35.38 \mathrm{~s}$ for $13.9 \mathrm{~h}$, with an angle of $120^{\circ}$ at $6 \mathrm{~V} / \mathrm{cm}$ and $14^{\circ} \mathrm{C}$. Gels were stained with a solution of ethidium bromide $(0.4 \mathrm{mg} / \mathrm{L}$; Promega) for $1 \mathrm{~h}$, then destained for $2 \mathrm{~h}$. Restriction patterns were visualized on a UV transilluminator (302 $\mathrm{nm}$ ), and images were captured using an AlphaImager 3300 Gel Documentation System (Alpha Innotech Corp., San Leandro, CA) and saved as .TIFF files for future analysis.

Banding patterns obtained for each strain from both the typical and modified methods were identical (Figure 1), confirming the suitability of this rapid method with samples of bifidobacteria.

Several modifications to the typical protocol were responsible for reducing the time needed to perform this technique. Most of the reduction in time for this method was associated with shorter incubation times during lysis, washing, and restriction.

Bifidobacteria are typically more difficult to lyse than gram negative bacteria, and PFGE protocols with bifidobacteria generally use long lysis times (18 to $72 \mathrm{~h}$ ). However, to reduce the lysis time, lysis reagents may be added to the initial cell suspension, then immediately combined with agarose to prevent undesirable shearing or degradation of the DNA, as recommended by Chang and Chui (1998). By adding lysozyme and proteinase $\mathrm{K}$ directly to the bifidobacteria cell suspension, incubation time in the lysis buffer with lysozyme and mutanolysin could be reduced to $90 \mathrm{~min}$. A higher incubation temperature $\left(55^{\circ} \mathrm{C}\right)$ was also used, which is closer to the temperature for maximum activity of the mutanolysin (Yokogawa et al., 1974). When the incubation time in this 


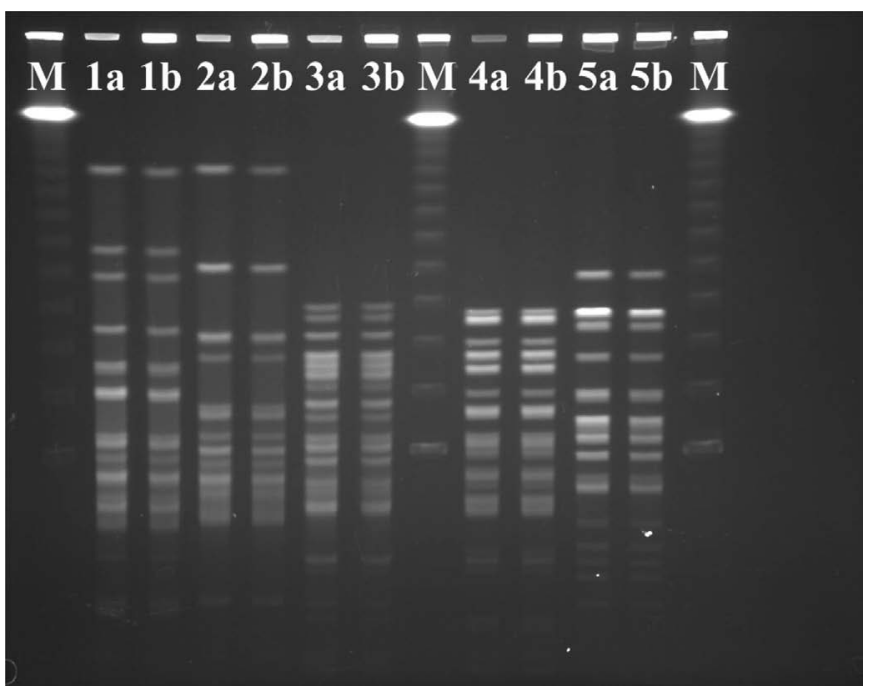

Figure 1. Pulsed-field gel electrophoresis comparing the traditional and rapid protocols, digested with $\mathrm{XbaI}$. M: Lambda molecular weight marker; lanes with "a" were performed with the traditional method, and lanes with "b" were performed with the rapid method; lanes 1a/b: Bifidobacterium breve ATCC 15698; lanes 2a/b: B. breve ATCC 15700; Lanes 3a/b: Bifidobacterium longum ATCC 15707; Lanes 4a/b: B. longum ATCC 15708; Lanes 5a/b: Bifidobacterium animalis ssp. lactis (commercial strain).

step was varied from $90 \mathrm{~min}$ to $18 \mathrm{~h}$, no difference in the intensity of the bands was observed. Although many of the bifidobacteria strains lysed without the addition of mutanolysin, it was necessary to add mutanolysin (200 units $/ \mathrm{mL}$ ) to the buffer to ensure complete lysis of all 34 strains examined. In an effort to reduce reagent costs associated with the modified method, subsequent experiments using a lower concentration of mutanolysin (40 units $/ \mathrm{mL}$ ) were performed, which resulted in complete lysis of 33 of the 34 strains of bifidobacteria within $1.5 \mathrm{~h}$. Therefore, this lower mutanolysin concentration of $40 \mathrm{units} / \mathrm{mL}$ has been used in our laboratory for routine PFGE analyses.

The incubation of the plugs in proteinase $\mathrm{K}$ buffer was also reduced from between 12 and $50 \mathrm{~h}$, as in traditional bifidobacterial protocols, to $60 \mathrm{~min}$ in the rapid protocol. When this step was varied between 1 and $4 \mathrm{~h}$, there was no difference in band intensity among the strains examined.

The washing steps were also modified from those of traditional PFGE protocols. Most protocols with bifidobacteria use PMSF, a serine protease inhibitor, to inactivate proteinase $\mathrm{K}$, followed by a series of washes to remove the PMSF (McCartney et al., 1996; Roy et al., 1996; Sanders et al., 1996; Kimura et al., 1997; Crittenden et al., 2001; Ventura and Zink, 2002; Yeung et al., 2002; Gueimonde et al., 2004; Mättö et al., 2004). Some protocols have extensively washed plugs to remove the proteinase $\mathrm{K}$ rather than inactivating it (Grand et al., 2003; O'Riordan and Fitzgerald, 1997). However, washing steps often will take up to $30 \mathrm{~h}$ in traditional methods. The rapid PFGE methods for Escherichia coli and Campylobacter, presented by Gautom (1997) and Michaud et al. (2001), respectively, suggested preheating the water or buffer and using a shaking water bath to shorten the time for this step. This procedure was applied in the rapid method for bifidobacteria-4 washes of $15 \mathrm{~min}$ each were performed with water and Tris, EDTA buffer at $50^{\circ} \mathrm{C}$-without negatively affecting the subsequent restriction of the DNA.

Restriction was also shortened from a traditional overnight incubation to $2 \mathrm{~h}$ without increasing the amount of enzyme used. Other rapid methods have used digest times between $90 \mathrm{~min}$ and $3 \mathrm{~h}$ (Matushek et al., 1996; Gautom, 1997; Chang and Chui, 1998; Michaud et al., 2001). A long incubation time was not necessary with samples prepared according to the rapid method based on the identical patterns obtained when digestion occurred over $18 \mathrm{~h}$.

A rapid PFGE method was developed for bifidobacteria that may be completed, from a turbid tube of culture media to a picture of a gel, within $24 \mathrm{~h}$. Although no effort was made to determine the minimum incubation times necessary at each step, the times reported here have been used successfully with our collection of bifidobacteria strains, suggesting that the long times used in traditional methods are unnecessary. This method should allow PFGE to be more readily applied to bifidobacteria isolates in the dairy and supplement industries.

\section{REFERENCES}

Basim, E., and H. Basim. 2001. Pulsed-field gel electrophoresis (PFGE) technique and its use in molecular biology. Turk. J. Biol. 25:405-418.

Bourget, N., J.-M. Simonet, and B. Decaris. 1993. Analysis of the genome of the five Bifidobacterium breve strains: Plasmid content, pulsed-field gel electrophoresis genome size estimation and $\mathrm{rrn}$ loci number. FEMS Microbiol. Lett. 110:11-20.

Busch, U., and H. Nitschko. 1999. Methods for the differentiation of microorganisms. J. Chromatogr. B: Biomed. Sci. Appl. 722:263-278.

Champagne, C. P., N. J. Gardner, and D. Roy. 2005. Challenges in the addition of probiotic cultures to foods. CRC Crit. Rev. Food Sci. Nutr. 45:61-84.

Chang, N., and L. Chui. 1998. A standardized protocol for the rapid preparation of bacterial DNA for pulsed-field gel electrophoresis. Diagn. Microbiol. Infect. Dis. 31:275-279.

Crittenden, R. G., L. F. Morris, M. L. Harvey, L. T. Tran, H. L. Mitchell, and M. J. Playne. 2001. Selection of a Bifidobacterium strain to complement resistant starch in a synbiotic yoghurt. J. Appl. Microbiol. 90:268-278.

Gautom, R. K. 1997. Rapid pulsed-field gel electrophoresis protocol for typing of Escherichia coli O157:H7 and other gram-negative organisms in 1 day. J. Clin. Microbiol. 35:2977-2980.

Grand, M., M. Küffer, and A. Baumgartner. 2003. Quantitative analysis and molecular identification of bifidobacteria strains in probiotic milk products. Eur. Food Res. Technol. 217:90-92. 
Gueimonde, M., S. Delgado, B. Mayo, P. Ruas-Madiedo, A. Margolles, and C. G. de los Reyes-Gavilán. 2004. Viability and diversity of probiotic Lactobacillus and Bifidobacterium populations included in commercial fermented milks. Food Res. Int. 37:839-850.

Kaufmann, P., A. Pfefferkorn, M. Teuber, and L. Meile. 1997. Identification and quantification of Bifidobacterium species isolated from food with genus-specific 16S rRNA-targeted probes by colony hybridization and PCR. Appl. Environ. Microbiol. 63:1268-1273.

Kimura, K., A. L. McCartney, M. A. McConnell, and G. W. Tannock. 1997. Analysis of fecal populations of bifidobacteria and lactobacilli and investigation of the immunological responses of their human hosts to the predominant strains. Appl. Environ. Microbiol. 63:3394-3398.

Matsuki, T., K. Watanabe, R. Tanaka, M. Fukuda, and H. Oyaizu. 1999. Distribution of bifidobacterial species in human intestinal microflora examined with 16S rRNA-gene-targeted species-specific primers. Appl. Environ. Microbiol. 65:4506-4512.

Mattila-Sandholm, T., P. Myllärinen, R. Crittenden, G. Mogensen, R. Fondén, and M. Saarela. 2002. Technological challenges for future probiotic foods. Int. Dairy J. 12:173-182.

Mättö, J., E. Malinen, M.-L. Suihko, M. Alander, A. Palva, and M. Saarela. 2004. Genetic heterogeneity and functional properties of intestinal bifidobacteria. J. Appl. Microbiol. 97:459-470.

Matushek, M. G., M. J. M. Bonten, and M. K. Hayden. 1996. Rapid preparation of bacterial DNA for pulsed-field gel electrophoresis. J. Clin. Microbiol. 34:2598-2600.

McCartney, A. L., W. Wenzhi, and G. W. Tannock. 1996. Molecular analysis of the composition of the bifidobacterial and lactobacillus microflora of humans. Appl. Environ. Microbiol. 62:4608-4613.

Michaud, S., R. D. Arbeit, and C. Gaudreau. 2001. Molecular strain typing of Campylobacter jejuni by pulsed-field gel electrophoresis in a single day. Can. J. Microbiol. 47:667-669.

O'Riordan, K., and G. F. Fitzgerald. 1997. Determination of genetic diversity within the genus Bifidobacterium and estimation of chromosomal size. FEMS Microbiol. Lett. 156:259-264.
Rosberg-Cody, E., R. P. Ross, S. Hussey, C. A. Ryan, B. P. Murphy, G. F. Fitzgerald, R. Devery, and C. Stanton. 2004. Mining the microbiota of the neonatal gastrointestinal tract for conjugated linoleic acid-producing bifidobacteria. Appl. Environ. Microbiol. 70:4635-4641.

Roy, D., P. Ward, and G. Champagne. 1996. Differentiation of bifidobacteria by use of pulsed-field gel electrophoresis and polymerase chain reaction. Int. J. Food Microbiol. 29:11-29.

Sanders, M. E., D. C. Walker, K. M. Walker, K. Aoyama, and T. R. Klaenhammer. 1996. Performance of commercial cultures in fluid milk applications. J. Dairy Sci. 79:943-955.

Simpson, P. J., C. Stanton, G. F. Fitzgerald, and R. P. Ross. 2002. Genomic diversity within the genus Pediococcus as revealed by randomly amplified polymorphic DNA PCR and pulsed-field gel electrophoresis. Appl. Environ. Microbiol. 68:765-771.

Simpson, P. J., C. Stanton, G. F. Fitzgerald, and R. P. Ross. 2003 Genomic diversity and relatedness of bifidobacteria isolated from a porcine cecum. J. Bacteriol. 185:2571-2581.

Ventura, M., R. Reniero, and R. Zink. 2001. Specific identification and targeted characterization of Bifidobacterium lactis from different environmental isolates by a combined multiplex-PCR approach. Appl. Environ. Microbiol. 67:2760-2765.

Ventura, M., and R. Zink. 2002. Rapid identification, differentiation, and proposed new taxonomic classification of Bifidobacterium lactis. Appl. Environ. Microbiol. 68:6429-6434.

Yeung, P. S. M., C. L. Kitts, R. Cano, P. S. Tong, and M. E. Sanders. 2004. Application of genotypic and phenotypic analyses to commercial probiotic strain identity and relatedness. J. Appl. Microbiol. 97:1095-1104.

Yeung, P. S. M., M. E. Sanders, C. L. Kitts, R. Cano, and P. S. Tong. 2002. Species-specific identification of commercial probiotic strains. J. Dairy Sci. 85:1039-1051.

Yokogawa, K., S. Kawata, S. Nishimura, Y. Ikeda, and Y. Yoshimura. 1974. Mutanolysin, bacteriolytic agent for cariogenic streptococci: Partial purification and properties. Antimicrob. Agents Chemother. 6:156-165. 